\title{
Pengawasan Atasan Langsung di Kantor Lembaga Penjamin Mutu Pendidikan Provinsi Sumatera Barat
}

Muhammad Rasyidi ${ }^{1}$, Sulastri Sulastri ${ }^{2}$, Jasrial $^{3}$, Nellitawati $^{4}$

${ }^{1}$ UniversitasNegeri Padang $1,{ }^{2}$ UniversitasNegeri Padang

Muhammad Rasyidi ${ }^{1}$, e-mail: rasyidm0202@gmail.com

Sulastri Sulastri² e-mail:sulastri_aip@fip.unp.ac.id

Jasrial $^{3}$ e-mail:jas.rial@yahoo.com

Nellitawati ${ }^{4}$ e-mail:nellitawati@ fip.unp.ac.id

\begin{abstract}
This research is based on the observations of the authors at the Office of the Quality Assurance Agency for Education of West Sumatra Province regarding the supervision of direct superiors that are still not well implemented. This research aims to obtain information on Direct Supervisory Supervision at the Education Quality Assurance Agency of West Sumatra Province as seen from the indicators of supervision procedures, supervision techniques, supervisory time and follow-up supervision. This research is descriptive with quantitative methods. The population of this research is employees in the Education Quality Assurance Agency of West Sumatra Province amounting to 76 employees, the sample taken is a population research so that the number of 76 respondents or all subjects in this study. Data collected using questionnaires. The average formulation is used in processing data in this research Data shows that direct supervisory supervision namely: (1) Supervision procedures get a score with an average of 4.26 fall into the good category; (2) Surveillance Techniques get a score with an average of 4.02 fall into the good category; (3) Supervised time scores with an average of 4.08 fall into the good category; (4) Follow-up supervision gets a score with an average of 3.66 belongs to the good category. Overall, Direct Supervisory Supervision at the Education Quality Assurance Agency of West Sumatra Province scored with an average of 4.00 in the good category.
\end{abstract}

\begin{abstract}
Abstrak
Penelitian ini berdasarkan pada hasil pengamatan penulis di Kantor Lembaga Penjamin Mutu Pendidikan Provinsi Sumatera Barat mengenai Pengawasan atasan langsung yang masih kurang diimplementasikan dengan baik. Penelitian ini bertujuan untuk mendapatkan informasi mengenai Pengawasan Atasan Langsung di Lembaga Penjamin Mutu Pendidikan Provinsi Sumatera Barat dilihat dari indikator prosedur pengawasan, Teknik pengawasan, Waktu pengawasan dan Tindak lanjut pengawasan. Kajian ini bersifat deskriptif dengan metode kuantitatif. Populasi penelitian ini yaitu Pegawai di Lembaga Penjamin Mutu Pendidikan Provinsi Sumatera Barat berjumlah 76 orang pegawai maka sampel yang diambil merupakan penelitian populasi sehingga berjumlah 76 responden atau seluruh subjek yang ada pada penelitian ini. Data yang dikumpulkan menggunakan angket. Rumusan rata-rata digunakan dalam mengolah data pada penelitian ini. Data menunjukan bahwa pengawasan atasan langsung yakni : (1) Prosedur pengawasan mendapatkan skor dengan rata-rata 4,26 termasuk dalam kategori baik; (2) Teknik Pengawasan mendapatkan skor dengan rata-rata 4,02 termasuk dalam kategori baik; (3) Waktu pengawasan mendapatkan skor dengan rata-rata 4,08 termasuk dalam kategori baik; (4) Tindak lanjut pengawasan mendapatkan skor dengan rata-rata 3.66 termasuk dalam kategori baik. Secara keseluruhan Pengawasan Atasan Langsung di Lembaga Penjamin Mutu Pendidikan Provinsi Sumatera Barat mendapatkan skor dengan rata 4.00 termasuk dalam kategori baik.
\end{abstract}

Kata Kunci:Pengawasan, Pengawasan langsung

How to Cite: Muhammad Rasyidi1, Sulastri Sulastri 2, Jasrial 3, Nellitawati 4, 2021.Pengawasan atasan langsung di Lembaga Penjamin Mutu Pendidikan Provinsi Sumatera Barat. Journal Educational Administrasi and Leadership, Vol (N): pp.XX-XX,DOI:10.24036/XXXXXXXXXX-X-XX 


\section{Pendahuluan}

Engkoswara \& Komariah (2011)) Pengawasan adalah suatu kegiatan yang dilakukan untuk mengetahui ada atau tidaknya penyimpangan yang dilakukan agar sesuai dengan rencana semula. Kegiatan pengawasan sangat penting dilakukan untuk sampai pada tujuan yang telah ditetapkan. direncanakan Ali (2013). Pengawasan atas yang efektif itu sangat penting dilakukan oleh pimpinan, pengawasan yang efektif dan dapat dilihat dari seringnya ia memantau karyawan dalam melaksanakan pekerjaannya, ataupun dengan menggunakan cara yang tepat dalam melakukan pengawasan tersebut.Pengawasan menurut LANRI (2003) dalam Usman (2013) adalah sebuah aktivitas untuk mendapatkan kejelasan tentang suatu kegiatan apakah telah terlaksana dengan baik.

Dari permasalahan yang penulis amati dan lihat di lapangan ialah proses pengawasan yang dilakukan pimpinan kurang mengacu pada langkah pengawasan, Pimpinan dalam melakukan pengawasan terhadap pegawai hanya menilai melalui laporan, Pimpinan masih kurang menggunakan teknik-teknik yang pengawasan langsung secara maksimal, dan Tindak lanjut yang dilakukan pemimpin terhadap kendalakendala yang dihadapi pegawai dalam melaksanakan pekerjaanya masih kurang.

Dari pemaparan diatas maka yang akan diteliti yaitu : 1) Bagaimana proses pengawasan atasan langsung di kantor Lembaga Penjamin Mutu Pendidikan Provinsi Sumatera Barat? 2) Bagaimana teknik pengawasan atasan langsung di Kantor Lembaga Penjamin Mutu Pendidikan Provinsi Sumatera Barat? 3) Bagaimana waktu pengawasan atas langsung di Kantor Penjamin Mutu Pendidikan Provinsi Sumatera Barat? 4) Bagaimana tindak lanjut pengawasan atasan langsung di Kantor Lembaga Penjamin Mutu Pendidikan Provinsi Sumatera Barat?

\section{Metode Penelitian}

Tempat yang dilakukan oleh peneliti ialah Kantor Lembaga .Penjamin Mutu Pendidikan Provinsi Sumatera Barat. Jenis riset ialah kuantitatif. Semua pegawai yang berjumlah 76 orang yang dijadikan populasi yang mana sebelumnya telah dilakukan uji coba di lembaga yang karakteristik sama dengan tempat penulis melakukan penelitian yaitu di Balai Bahasa Provinsi Sumatera Barat. Riset ini menggunakan angket, rumus rata-rata yang dilakukan untuk memperoleh data hasil penelitian.

\section{Hasil dan Bahasan}

\subsection{Hasil}

Berdasarkan hasil pengolahan data penelitian berikut dijelaskan satu persatu menurut indikator peneliti:

Secara keseluruhan skor rata-rata tentang Pengawasan atasan langsung dilihat dalam hal: a) Prosedur pengawasan adalah 4,26 berkategori baik, hal ini diartikan bahwa prosedur pengawasan yang dilakukan atasan langsung di Kantor Lembaga Penjamin Mutu Pendidikan Provinsi Sumatera Barat sudah baik serta perlu untuk ditingkatkan lagi menjadi lebih baik. b) Teknik pengawasan adalah 4,02 berkategori baik, hal ini dikatakan bahwa teknik pengawasan yang dilakukan atasan langsung di Kantor Lembaga Penjamin Mutu Pendidikan Provinsi Sumatera Barat telah terlaksana dengan baik. c) Waktu pengawasan adalah 4,08 berkategori baik, hal ini diartikan waktu pengawasan yang dilakukan atasan langsung di Kantor Lembaga Penjamin Mutu Pendidikan Provinsi Sumatera Barat telah terlaksana dengan baik. d) Tindak lanjut pengawasan adalah 3,66 berkategori baik, hal ini dapat diartikan bahwa tindak lanjut pengawasan yang dilakukan atasan langsung di Kantor Lembaga Penjamin Mutu Pendidikan Provinsi Sumatera Barat telah terlaksana dengan baik tapi perlu untuk ditingkatkan lagi.

\subsection{Pembahasan}

Berdasarkan hasil dari penelitian Pengawasan Atasan Langsung di Kantor Lembaga Penjamin Mutu Pendidikan Provinsi Sumatera Barat terdapat perolehan data dengan nilai rata-rata yakni 4,00 dengan kategori baik dilihat dalam hal ini yakni :1) Prosedur pengawasan mendapatkan skor dengan rata-rata 4,26 termasuk dalam kategori baik, 2) Teknik pengawasan mendapatkan skor dengan rata-rata dengan 4,02 termasuk dalam kategori baik, 3) Waktu pengawasan mendapatkan skor dengan rata-rata dengan 4,08 termasuk dalam kategori baik , 4) Tindak lanjut pengawasan mendapatkan skor dengan rata-rata 3,66 termasuk dalam kategori baik.

a. Prosedur Pengawasan

Dari pengolahan hasil data penelitian yang ditinjau dari aspek Prosedur pengawasan mendapat skor rata-rata 4,26 angka menunjukan hasil baik. Berdasarkan skor rata-rata tertinggi adalah "Pegawai diberi pekerjaan sesuai dengan tugas pokoknya" dengan skor rata-rata 4,45 menurut Sagala(2011) setiap 
pekerjaan yang diberikan kepada bawahan haruslah sesuai dengan tugasnya. Sedangkan skor terendah yakni "Pegawai diberi format pengawasan oleh pimpinan untuk di isi" dengan skor rata-rata 3,74. Sehingga dalam hal ini mengenai skor terendah maka atasan atau pimpinan perlu meningkatkan lagi prosedur pengawasan dalam hal pemberian format pengawasan untuk diisi oleh para bawahan atau anggota.

b. Teknik Pengawasan

Dari pengolahan hasil data penelitian ditinjau dari aspek Teknik pengawasan mendapatkan skor dengan rata-rata 4,02 termasuk dalam kategori baik. Hal ini dilihat dari skor tertinggi adalah "Pimpinan memeriksa pekerjaan yang dikerjakan oleh pegawai" mendapatkan skor dengan rata-rata 4,28. Selanjutnya dengan skor terendah yaitu "Pimpinan melakukan sidak (inspeksi mendadak) saat melakukan pengawasan" berada pada skor rata-rata 3,78. Pada saat melakukan sidak, pimpinan akan melakukan tanya jawab langsung dengan pegawai dan pimpinan akan memperoleh laporan langsung dari pegawai Terry(2012). Dalam hal ini sebagai seorang pimpinan perlu melakukan sidak yang tujuannya agar pegawai lebih giat dan lebih disiplin dalam bekerja, dan pegawai tidak hanya bekerja ketika ada pimpinan saja.

c. Waktu Pengawasan

Dari pengolahan hasil data penelitian ditinjau dari aspek Waktu pengawasan mendapatkan skor ratarata 4,08 termasuk dalam kategori baik. Hal ini dilihat dari skor tertinggi adalah "Pimpinan melakukan pengawasan sebelum suatu kegiatan dilakukan" mendapatkan skor dengan rata-rata 4,16. Selanjutnya dengan skor terendah yaitu "Pegawai diminta oleh pimpinan untuk membuat laporan mingguan" dengan skor rata-rata 3,72.sebagai seorang karyawan haruslah membuat laporan baik itu laporan lisan atau tulisan, dilakukannya pembuatan laporan ini agar setiap kegiatan yang dilakukan untuk menjabarkan secara rinci proses dari pelaksanaan suatu kegiatan yang dilakukan, mulai dari sebelum kegiatan dilakukan, pada saat kegiatan dilakukan dan setelah kegiatan dilakukan, Handoko(2011). Kepada pegawai hendaknya membuat laporan yang gunanya nanti sebagai bahan penilaian bagi pimpinan.

d. Tindak Lanjut Pengawasan

Dari pengolahan hasil data penelitian ditinjau dari aspek Tindak lanjut pengawasan mendapatkan skor rata-rata 3,66 yang menunjukkan hasil baik. Berdasarkan skor dengan rata-rata tertinggi adalah "Pimpinan memberikan peringatan (SP) sebelum menjatuhkan sanksi" mendapatkan skor dengan rata4,33. Selanjutnya pada skor dengan rata-rata yang terendah adalah "Pegawai yang melakukan pelanggaran yang dianggap berat akan diserahkan kepada pihak yang berwajib" dengan skor rata-rata 2,50

Bertujuan agar memberikan efek jera kepada karyawan yang melakukan pelanggaran berat dan melanggar aturan. Pengawasan ini akan lebih baik lagi kedepannya apabila seorang pemimpin menindak tegas bawahannya yang melakukan pelanggaran, upaya yang dapat dilakukan bisa saja dengan menyerahkan kepada pihak berwajib apabila pelanggaran yang dilakukan oleh pegawai itu sudah dianggap berat.

\section{Kesimpulan}

Kesimpulan hasil dari penelitian mengenai Pengawasan Atasan Langsung di Kantor Lembaga Penjamin Mutu Pendidikan Provinsi Sumatera Barat dilihat dalam hal Prosedur pengawasan mendapatkan skor dengan rata-rata 4,26 termasuk dalam kategori baik. berkategori baik. Teknik pengawasan mendapatkan skor dengan rata-rata 4,02 termasuk dalam kategori baik. Waktu pengawasan mendapatkan skor dengan rata-rata 4,08 termasuk dalam kategori baik. Dan Tindak lanjut pengawasan mendapatkan skor dengan rata-rata 3,66 termasuk dalam kategori baik. Secara umum Pengawasan Atasan Langsung di Kantor Lembaga Penjamin Mutu Pendidikan Provinsi Sumatera Barat mendapatkan skor dengan rata-rata 4,00 termasuk dalam kategori baik.

Dengan demikian kesimpulan diatas,tentang Pengawasan Atasan Langsung di Kantor Lembaga Penjamin Mutu Pendidikan Provinsi Sumatera Barat bisa dikatakan sudah terlaksana dengan baik sesuai dengan angket yang telah diisi oleh pegawai untuk itu masih perlunya adanya peningkatan dari pengawas/pimpinan dalam menunjang nya peningkatan pengawasan dalam mencapai kategori sangat baik agar dapat terlaksana dengan optimal.

\section{Daftar Rujukan}

Ali, I. (2013). Proses Manajemen Tingkat Satuan Pendidikan. PT Bumi Aksara. 
Engkoswara, \& Komariah, A. (2011). Administrasi Pendidikan. Alfabeta.

Handoko. (2011). Manajemen Edisi Kedua. BPFE.

Sagala. (2011). Administrasi Pendidikan Kontemporer. Alfabeta.

Terry, G. (2012). Prinsip-Prinsip Manajemen. PT Bumi Aksara.

Usman, H. (2013). Manajemen (Edisi 4). PT Bumi Aksara. 